\title{
Qualidade e eqüidade em educação: reconsiderando o significado de "fatores intra-escolares" *
}

\section{Resumo}

$\mathrm{O}$ artigo investiga quais características escolares estão associadas ao aumento do desempenho médio das escolas medido por meio dos testes de Matemática, da $4^{a}$ série do Ensino Fundamental, pelo SAEB 2001. Investiga, especificamente, características escolares promotoras de eficácia escolar e de eqüidade intra-escolar, e identifica e avalia o efeito sobre a eqüidade de características escolares associadas, simultaneamente, à eficácia escolar e ao aumento das desigualdades dentro das unidades escolares.

Palavras-chave: Fatores intra-escolares. Eficácia escolar. Eqüidade intra-esco-

\section{Creso Franco}

Doutor em Educação, University of

Reading, Inglaterra creso@edu.puc-rio.br

\section{Isabel Ortigão}

Doutora em Educação, PUC-Rio

Ângela Albernaz

Mestre em Economia, PUC-Rio

\section{Alicia Bonamino}

Doutora em Educação, PUC-Rio alicia@edu.puc-rio.br

\section{Glauco Aguiar}

Mestre em Educação, PUC-Rio

Fátima Alves

Doutora em Educação, PUC-Rio

Natália Sátyro

Mestre em Ciências Políticas, IUPERJ

lar. Educação fundamental.

Abstract

Quality and equality in education: reconsidering the meaning of "within-school factors"

This paper deals with the issue of quality and equality in schools. The empirical investigation is based on data of Brazilian national assessment, mathematics, grade $4^{\text {th }}$, carried out in 2001. Findings stress that school factors associated to quality are also associated to

"Este texto é uma versão ampliada de Franco et al. (2006). Os autores agradecem pelo apoio recebido do Preal, da Fundação Ford, do CNPq e da Faperi. 
within-school inequality. In this context, we discuss to what extent and under which conditions features associated to quality may also be associated to within school system equity.

Keywords: School factors. school effectiveness. Equity. Primary education.

\section{Resumen}

\section{Calidad y equidad en} educación:

\section{reconsiderando el} significado de "factores intra-escolares"

Este artículo investiga que características escolares están asociadas al aumento en el desempeño medio de las escuelas medido, por el test de matemática de $4^{\circ}$ grado de la escuela fundamental, aplicado por la evaluación nacional de la educación básica brasileña - SAEB 2001. Investiga, específicamente, características escolares promotoras de eficacia escolar y de equidad intra-escolar, e identifica y evalúa el efecto sobre la equidad de características escolares asociadas, simultáneamente, a la eficacia escolar e al aumento de las desigualdades dentro de las unidades escolares.

Palabras clave: Factores intraescolares. Eficacia escolar. Equidad intraescolar. Educación fundamental.

"[O diretor] tinha maneiras de todos os graus, segundo a condição social da pessoa [...] E duramente se marcavam distinções políticas, distinções financeiras, distinções baseadas na crônica escolar do discípulo, baseadas na razão discreta das notas do guarda-livros. Às vezes, uma criança sentia a alfinetada no jeito da mão a beijar. Saía indagando consigo o motivo daquilo, que não achava em suas contas escolares [...] $\bigcirc$ pai estava dois trimestres atrasado". Raul Pompéia, em O Ateneu.

\section{Introdução}

Na Reunião Anual da Anped de 1979 ocorreu uma mesa-redonda sobre seletividade socioeconômica no ensino de $1^{\circ}$ grau. Os textos básicos da discussão estão disponíveis em Goldberg et al. (1981). Tempos difíceis aqueles. No plano político, o destaque era a falta de democracia. No plano acadêmico, ênfase nas abordagens críticoreprodutivistas, o que não deixou de se expressar na mencionada mesa-redonda. Pelo menos uma das contribuições apresentadas sublinhava claramente que a seletividade socioeconômica operava por meio de fatores intra-escolares e que esses mecanismos seriam suscetíveis de serem atenuados por meio de políticas públicas baseadas em evidências de pesquisa educacional de boa qualidade (MELLO, 1979, 1981). Uma das idéias apresentadas por Mello foi rigorosamente desprezada pela área de Educação a que preconizava o papel de evidências para políticas educacionais - enquanto a outra - a que enfatizava o papel dos "fatores intraescolares" - teve grande repercussão na área, especialmente a partir do resultado das eleições de 1982, que determinou grande diversificação nos agentes responsáveis pela formulação e implantação de políticas educacionais no âmbito dos estados e das prefeituras das capitais.

artigo de Mello (1979) é um marco de um movimento intelectual da autora e de muitos outros pesquisadores que procuravam superar a visão que não apenas sobre-enfatizava o caráter reprodutor da 
educação, mas também deixava de considerar o modo e os mecanismos especificamente educacionais pelos quais a reprodução social efetivamente ocorre. A despeito do avanço que este movimento significou para a pesquisa educacional, devemos registrar que o argumento acerca dos "fatores intraescolares" foi apresentado à época como característico da unidade escolar, não contemplando, portanto, a possibilidade de que tais fatores afetassem de modo distinto alunos da unidade escolar pertencentes a diferentes grupos sociais. De modo mais geral, a pesquisa da época tinha especial dificuldade em lidar simultaneamente com mais de uma unidade de análise. Tipicamente, as investigações assumiam a escola ou os alunos como a unidade de análise, limitação ainda freqüentemente presente na pesquisa educacional contemporânea.

Como bem ilustra o texto de Raul Pompéia, escrito no final do século XIX e usado como epígrafe neste artigo, muitas vezes a literatura se adianta em questões que a investigação científica ainda não está preparada para enfrentar analiticamente (CHOMSKY, 1987). No presente artigo apresentamos a estratégia mais usada atualmente para superar o problema da escoIha da unidade de análise na pesquisa educacional quantitativa e aplicamos esta estratégia em investigação sobre como fatores intraescolares relacionam-se simultaneamente com eficácia escolar - isto é, com o desempenho médio das escolas - e com eqüidade intraescolar, isto é, com a distribuição social do desempenho escolar dos alunos dentro das escolas. Por esta via, procuramos ilustrar como os fatores escolares podem explicar desigualdades entre escolas e dentro das escolas.

\section{Objetivos e questões de pesquisa}

Durante a maior parte do século XX o Brasil apresentou indicadores educacionais bastante desfavoráveis, não só em comparação com países europeus, mas também em comparação com a maior parte dos países latino-americanos. Nos últimos quinze anos o Brasil melhorou sensivelmente seus indicadores de acesso e de fluxo de crianças e jovens na escola, (SCHWARTZMAN, 2000). No entanto, ainda persistem problemas com o fluxo de alunos (FRANCO, 2004) e, em especial, com a qualidade da educação ministrada nas escolas brasileiras (INEP, 2002, 2004). Os resultados da participação do Brasil em avaliações em larga escala indicam que o nível médio da performance de alunos brasileiros é próximo ao de alunos chilenos, argentinos e mexicanos, bem inferior ao de alunos cubanos, e levemente superior ao de vários países latino-americanos (UNESCO, 2000; OECD, 2004). Quando comparados com resultados de países da Organization for Economic Cooperation and Development OECD, o desempenho de alunos brasileiros tem se mostrado bastante baixo (OECD, 2004; INEP, 2002; LEE; FRANCO; ALBERNAZ, 2004), o que é particularmente preocupante no contexto de crescente integração econômica em escala mundial.

Além de problema com a qualidade da educação, a sociedade brasileira precisa enfrentar questões relativas à eqüidade. Investigação da OECD (2004), indica que o Brasil é um dos países nos quais a correlação entre o nível socioeconômico e cultural dos alunos e as condições escolares associadas à eficácia escolar possui maior magnitude. Neste contexto, o presente estudo faz uso de 
dados da avaliação nacional da educação, através do Sistema de Avaliação da Educação Básica - SAEB (INEP, 2001), para investigar as seguintes questões (SAEB 2001, 4 ${ }^{a}$ série, matemática):

(i) Que características escolares estão associadas ao aumento no desempenho médio das escolas medido pelo teste de matemática do SAEB?

(ii) Que características escolares diminuem o impacto do nível socioeconômico dos alunos no desempenho de discentes que freqüentam as mesmas unidades escolares?

(iii) Como avaliar o impacto global sobre a eqüidade educacional das características escolares associadas simultaneamente ao aumento da média da escola e ao aumento, dentro das escolas, do efeito do nível socioeconômico no desempenho escolar dos alunos?

Em resumo: a primeira questão de pesquisa investiga características escolares promotoras de eficácia escolar; a segunda questão debruça-se sobre o tema da eqüidade intraescolar; e a terceira questão busca identificar e avaliar o efeito sobre a eqüidade de características escolares associadas simultaneamente à eficácia escolar e ao aumento das desigualdades dentro das unidades escolares.

Este artigo começa apresentando os conceitos de eficácia e eqüidade e expõe uma revisão dos estudos empíricos brasileiros sobre o tema. Segue com o delineamento do método utilizado na investigação empírica e com a apresentação e discussão dos resultados. Finalmente, sintetiza os principais achados e discute as implicações para políticas públicas.

\section{Eficácia e eqüidade escolar: os conceitos de eficácia e de eqüidade escolar}

De acordo com Mortimore (1991), escola eficaz é aquela que viabiliza que seus alunos apresentem desempenho educacional além do esperado, face à origem social dos alunos e à composição social do corpo discente da escola. A investigação que assume a definição de Mortimore busca identificar as unidades escolares que possuem alto desempenho educacional, após a filtragem dos efeitos atribuíveis às características individuais dos alunos e à composição social do corpo discente das escolas. Uma abordagem alternativa é a que, ao invés de procurar identificar as unidades escolares eficazes, busca caracterizar quais políticas e práticas escolares podem explicar o alto desempenho educacional de escolas, sempre após filtrar os efeitos atribuíveis às características individuais dos alunos e à composição social do corpo discente das escolas (RAUDENBUSH; BRYK, 2002). Neste artigo procuramos identificar políticas e práticas escolares associadas a alto desempenho escolar de alunos da $4^{a}$ série do Ensino Fundamental nos testes de Matemática do SAEB 2001.

conceito de desigualdade intraescolar refere-se ao processo de produção de desigualdade no desempenho escolar de alunos que freqüentam a mesma unidade escolar, muitas vezes via mecanismos sutis, outras vezes por meio de mecanismos explícitos, como o exemplificado na epígrafe do presente artigo. Fatores promotores de eqüidade intraescolar são aqueles que propiciam a moderação (e, eventualmente, a su- 
peração) da desigualdade no desempenho escolar de alunos que freqüentam as mesmas unidades escolares. Buscamos identificar características escolares que moderam o efeito da origem social dos alunos - neste artigo focalizamos especificamente eqüidade socioeconômica, mas a discussão conceitual aqui apresentada pode ser usada no contexto de eqüidade racial ou de eqüidade de gênero - sobre o desempenho em matemática nos testes do SAEB 2001.

conceito de eqüidade intraescolar não deve ser considerado de modo independente do conceito de eficácia. $O$ cenário mais positivo ocorre quando as características associadas à eqüidade intraescolar também estão associadas à eficácia escolar. Neste caso, um mesmo conjunto de práticas escolares atua, concomitantemente, no sentido de aumentar o desempenho médio das escolas e de promover distribuição mais equânime do desempenho escolar dos alunos que freqüentam as mesmas unidades escolares. Já o mesmo não ocorre quando uma característica que modera o efeito da origem social no desempenho escolar está associada a baixo desempenho escolar dos alunos, pois não faz sentido considerar como pró-eqüidade prática educativa que está associada a baixo desempenho escolar. Finalmente, faz-se necessário considerar a situação em que as mesmas políticas e práticas escolares estão associadas, simultaneamente, ao aumento da eficácia escolar e à diminuição da eqüidade intraescolar. Examinaremos esse caso mais complexo mais à frente, à luz de resultados obtidos no presente artigo. Por enquanto, apenas adiantamos que este último caso só poderá ser tratado adequadamente em quadro conceitual que inclua um conceito adicional, nomeadamente o de eqüidade no sistema educacional, que será operacionalizado mais à frente, a partir da consideração conjunta tanto do efeito pró-eficácia quanto do efeito anti-eqüidade intraescolar de certas políticas e prática educativas.

\section{Pesquisas prévias no Brasil}

No cenário internacional, a tradição de pesquisa sobre eficácia e eqüidade escolar já está bem consolidada e há algumas revisões clássicas da literatura internacionais (SAMMONS; HILLMAN; MORTIMORE, 1995; LEE; BRYK; SMITH, 1993; MAYER; MULLENS; MOORE, 2000). Para uma revisão dessas revisões e considerações sobre o contexto educacional brasileiro pode-se consultar Franco, Fernandes, Soares, Beltrão, Barbosa e Alves (2003). Ainda que a utilização dos dados disponibilizados no Brasil a partir das experiências de sistemas de avaliação da educação esteja aquém do desejável, já começa a se constituir um núcleo de publicações sobre eficácia escolar baseado em dados brasileiros. ' Esta seção está dedicada à revisão desta literatura brasileira, ainda que, mais à frente, recuperemos os aspectos da literatura internacional que se mostram relevantes para a discussão dos achados da presente investigação.

Para além das variáveis relacionadas com a composição social da escola, que devem ser consideradas como variáveis de controle, os fatores escolares associados à eficácia escolar descritos na literatura bra-

\footnotetext{
' Em sentido estrito, a investigação sobre eficácia escolar é baseada em dados longitudinais de painel, de modo a evitar as bem conhecidas limitações de investigação de relações causais com base em dados seccionais. Face à inexistência de dados longitudinais de painel de boa qualidade no contexto brasileiro, a produção nacional ainda está baseada em dados seccionais.
} 
sileira podem ser organizados em cinco categorias: (a) recursos escolares; (b) organização e gestão da escola; (c) clima acadêmico; (d) formação e salário docente; (e) ênfase pedagógica. Cada um desses temas é apresentado abaixo. ${ }^{2}$

Recursos escolares: no Brasil, equipamentos e conservação do equipamento e do prédio escolar importam. Resultados neste sentido, com base nos dados do SAEB 2001, 8 ${ }^{a}$ série (INEP, 2001), foram reportados por Franco, Sztajn e Ortigão (2007) e por Soares (2004)3. Na mesma linha, Lee, Franco e Albernaz (2004) encontraram efeito positivo da infra-estrutura física da escola sobre o desempenho em leitura dos alunos brasileiros que participaram do Programa Internacional de Avaliação de Estudantes - PISA 2000 (OECD, 2001, 2004). Espósito, Davis e Nunes (2000) encontraram resultados positivos para o efeito das condições de funcionamento de laboratórios e espaços adicionais para atividades pedagógicas. Albernaz, Ferreira e Franco (2002) reportaram o efeito negativo sobre a eficácia escolar da falta de recursos financeiros e pedagógicos da escola, a partir de dados do SAEB 1999, 8ª́rie. O mesmo resultado foi obtido tanto por Franco, Sztajn e Ortigão (2007) quanto por Soares (2004), a partir de dados do SAEB 2001, 8ª série. Em muitos países, recursos escolares não são fatores de eficácia escolar. A razão disto é que o grau de equipamento e conser- vação das escolas não varia muito de escola para escola e que praticamente todas as escolas possuem recursos básicos para funcionamento. No Brasil, ainda temos bastante variabilidade nos recursos escolares com que contam as escolas, o que explica os resultados reportados acima. Deve, ainda, ser enfatizado que a pura e simples existência dos recursos escolares não é condição suficiente para que os recursos façam diferença: faz-se necessário que eles sejam efetivamente usados de modo coerente no âmbito da escola.

Organização e gestão da escola: em estudo baseado em dados do SAEB 2001, 8a série, tanto Franco, Sztajn e Ortigão (2007) quanto Soares e Alves (2003) reportaram que o reconhecimento por parte dos professores da liderança do diretor é característica associada à eficácia escolar. Tanto Espósito, Davis e Nunes (2000), com base em dados do Sistema de Avaliação de Rendimento do estado de São Paulo (SARESP), quanto Soares (2004), a partir de dados do SAEB 2001, reportaram efeito positivo sobre a eficácia escolar de variável que captava responsabilidade coletiva dos docentes sobre os resultados dos alunos. Na mesma linha, mas a partir dos dados do PISA 2000 para o Brasil, Lee, Franco e Albernaz (2004) registraram que a responsabilidade coletiva dos docentes, medida pelo empenho coletivo dos docentes quanto ao aprendizado dos alunos, é fator relevante para a eficácia escolar. Esses resul-

\footnotetext{
${ }^{2}$ Não incluímos na presente revisão estudos que deixaram de implementar controle pelo nível socioeconômico do corpo discente da escola, pois sem o mencionado controle a análise tende a produzir muitos resultados 'falsos positivos', devido à alta correlação entre boas condições escolares e alto nível socioeconômico da escola. Além disto, concentramos nossa revisão em trabalhos que passaram por processo de revisão por pares (artigos de periódicos e trabalhos apresentados em eventos que avaliam previamente os trabalhos publicados e/ou apresentados). Outros tipos de trabalho foram considerados apenas nos casos em que ajudavam a esclarecer polêmicas relacionadas com os trabalhos que passaram pela revisão de pares.

${ }^{3}$ Soares (2004) optou por investigar o efeito de cada um dos fatores escolares por ele considerados separadamente, testando o efeito de cada variável escolar em um modelo básico, que consistia em um modelo com as variáveis usuais de nível-1 e o controle de nível-2 por tipo de escola e composição social da escola. Os demais autores considerados nesta seção incluíram diversas variáveis escolares simultaneamente em seus modelos básicos, que eram, tipicamente, semelhantes ao modelo básico de Soares (2004).
} 
tados estão em sintonia com os achados de pesquisas conduzidas internacionalmente.

Clima acadêmico: diversas características escolares relacionadas com a ênfase acadêmica da escola - isto é, com a primazia do ensino e da aprendizagem, a despeito de as escolas eventualmente lidarem com outras demandas sociais mais amplas - mostraram-se associadas à eficácia escolar. A ênfase em passar e corrigir dever de casa foi reportada por Franco, Sztajn e Ortigão (2007), em estudo baseado no SAEB 2001, 8a série, e por Machado Soares (SOARES, 2003, 2005) em estudos baseados em dados da avaliação estadual mineira de 2002, 4ª série. Nos mesmos estudos citados, Machado Soares enfatizou, ainda, o efeito positivo tanto do interesse e dedicação do professor quanto do nível de exigência docente sobre o desempenho médio das escolas. Face à forte conexão conceitual entre essas variáveis - o que sugere alta correlação entre elas - a concomitante presença das três variáveis mencionadas nos estudos de Machado Soares indica a alta relevância de variáveis relativas ao clima acadêmico da escola. Ademais, a exigência docente foi também reportada por Lee, Franco e Albernaz (2004) em investigação baseada nos dados do PISA 2000 (OECD, 2001, 2004). Os estudos de Machado Soares (2003, 2005) enfatizaram que o absenteísmo docente tem efeito regressivo sobre a eficácia escolar e o estudo de Lee, Franco e Albernaz (2004), baseado em dados do PISA 2000, indicou o efeito regressivo do absenteísmo discente tanto sobre a eficácia escolar quanto sobre a eqüidade intraescolar, já que nas escolas em que o absenteísmo discente era problema esta variável estava associada não só a menor desempenho médio dos alunos, mas também ao aumento do efeito do nível socioeconômico dos alunos em seus resultados escolares. Na mesma linha, Soares (2004) reportou efeito positivo sobre a eficácia escolar e a eqüidade intraescolar de escala construída a partir de variáveis que mediam tanto a ausência de absenteísmo discente e docente quanto de problemas disciplinares e violência. ${ }^{4}$

Formação e salário docente: diferentemente dos temas acima considerados, os achados relacionados com formação e salário docente são esparsos, a magnitude dos efeitos é relativamente pequena e a significância estatística dos achados pode não ser tão robusta quanto as anteriormente mencionadas, como ficará claro mais à frente. Albernaz, Ferreira e Franco (2002) reportaram efeito positivo sobre a eficácia escolar para o variável nível de formação docente, em estudo baseado em dados do SAEB 1999. Neste mesmo estudo, os autores reportaram também efeito positivo para a variável 'salário do professor', mas ambas as variáveis perdiam significância estatística se incluídas conjuntamente no mesmo modelo, resultado que sugere a existência de alta correlação entre nível de formação e salário de professores. A partir de dados do SAEB 2001, Soares (2004) reportou resultados

\footnotetext{
${ }^{4} \mathrm{O}$ tema da literatura brasileira sobre eqüidade e eqüidade intraescolar é amplo e seu tratamento vai além dos objetivos dessa revisão. Resultados empíricos sobre eqüidade intraescolar na dimensão socioeconômica, racial ou de gênero podem ser encontrados em Albernaz, Ferreira e Franco (2002), Franco, Mandarino e Ortigão (2002), Andrade, Franco e Carvalho (2003), Soares (2004), Bonamino, Franco e Alves (2005) e Franco, Sztajn e Ortigão (2007). Este último trabalho elabora também a distinção entre eqüidade intraescolar e eqüidade no sistema escolar, apresentando referencial para a interpretação da situação na qual variável escolar promove, simultaneamente, eficácia escolar e desigualdade intraescolar.
} 
convergentes com os de Albernaz, Ferreira e Franco (2002). Face à relevância do tema, é recomendável que outros autores investiguem o tema a partir de outras bases de dados. Já o estudo de Menezes e Pazello (2004) faz uso de dados do SAEB de 1997 e 2001 para investigar o efeito do Fundo de Manutenção e Desenvolvimento do Ensino Fundamental e de Valorização do Magistério - FUNDEF, sobre salários e desempenho nos testes do SAEB. Trata-se, portanto, de investigação que foge à configuração geral dos estudos de eficácia escolar, mas que, ainda assim, é revisto aqui face à conexão do tema com a eficácia escolar. A metodologia dos autores baseia-se na adoção de um grupo de controle - as escolas privadas - com o qual é comparado o grupo de escolas que poderiam ser influenciadas pelo FUNDEF. Os resultados indicaram a diminuição, no período considerado, da diferença em favor das escolas privadas tanto do salário de professores quanto do desempenho dos estudantes. Este efeito foi particularmente relevante na região nordeste.

Ênfase pedagógica: Franco, Sztajn e Ortigão (2007) obtiveram resultados positivos em investigação sobre o efeito de 'ênfase em ensino orientado pela reforma da educação matemática', isto é, ênfase em raciocínios de alta ordem e em resolução de problemas genuínos e contextualizados, no desempenho em Matemática dos alunos testados pelo SAEB 2001, 8a série. Usando a mesma base de dados (SAEB 2001), mas com estratégia distinta de construção da variável sobre estilo pedagógico do professor, com especificação distinta do modelo no qual o efeito da variável que caracterizava o estilo pedagógico era testado e tendo analisado os dados da $4^{a}$ e $8^{a}$ séries do Ensino Fundamental e da $3^{a}$ série do Ensino Médio, Franco, Fernandes, Soares, Beltrão, Barbosa e Alves (2001) encontraram, antes da implementação de controle pelo nível socioeconômico médio da escola, efeito positivo associado aos métodos ativos de ensino. No entanto, o efeito tornou-se estatisticamente nulo quando da implementação do controle pelo nível socioeconômico médio das escolas. A discrepância dos resultados deve estimular os pesquisadores a investigarem o assunto de modo mais sistemático e profundo.

Em resumo, a revisão da literatura brasileira sobre eficácia escolar tem achados convergentes sobre o efeito positivo dos recursos escolares - ainda que os pesquisadores entendam que recursos só podem ser eficazes quando efetivamente utilizados - da organização e gestão da escola - baseada em liderança do diretor e em comprometimento coletivo do corpo docente com o aprendizado de seus alunos - e do clima acadêmico orientado para as exigências acadêmicas do processo de ensino e de aprendizagem. A literatura examinada produziu também evidências, ainda que mais esparsas, em favor do efeito positivo do nível educacional de professores, do salário de professores e de estilo pedagógico sintonizado com o movimento de renovação do ensino de Matemática.

\section{Método Dados}

Nesse artigo utilizamos os dados provenientes do SAEB 2001 (INEP, 
2001), referente a $4^{a}$ série do Ensino Fundamental, Matemática, que envolveu 57.258 alunos em 5.151 turmas e 4.065 escolas. Os estudantes fizeram um teste de múltipla escolha de Matemática e uma medida de proficiência, baseada na Teoria de Resposta ao Item, foi atribuída a cada um dos alunos. Os estudantes também responderam a um questionário sobre aspectos relacionados à origem socioeconômica e cultural, práticas de estudos e ênfase dada pelos professores ao dever de casa. Diretores e professores também responderam a um questionário envolvendo tópicos sobre recursos escolares, organização e gestão da escola, clima acadêmico e práticas pedagógicas.

O SAEB é baseado em uma amostra probabilística complexa, estratificada por estado e por dependência administrativa das escolas (privadas, públicas estaduais e públicas municipais). As unidades primárias de amostragem são as escolas e as secundárias são as turmas. Quando uma turma de uma escola é selecionada, todos os alunos desta turma fazem parte da amostra do SAEB, mas apenas metade dos alunos faz o teste de Matemática pois a outra metade responde ao teste de Leitura.

\section{Medidas}

A variável dependente é o desempenho do aluno no teste de matemática obtida via Teoria de Resposta ao Item. As análises desenvolvidas aqui se referem somente aos alunos que fizeram 0 teste de matemática. A escolha desta disciplina relaciona-se com o caráter tipicamente escolar do conhecimento matemático, em comparação com o conhecimento da língua nativa, que, necessariamente, é desenvolvido nos diversos ambientes freqüentados pelos jovens.

As seguintes variáveis escolares foram incluídas no modelo: Demanda por Dever de Casa, Biblioteca na Sala de Aula e Bom Clima Disciplinar - como indicadores da ênfase acadêmica -, Existência e Conservação de Equipamentos e Existência de Pessoal e Recursos - como indicadores de recursos escolares -, Ênfase em Resolução de Problemas, como indicador de ênfase pedagógica, e Liderança Colaborativa como indicador de organização e gestão da escola. Variáveis do aluno foram também incluídas no modelo, são elas: Gênero, Repetência (como indicador de trajetória escolar prévia) e Nível Socioeconômico - NSE, do Aluno. Além disto, implementou-se controle por Nível Socioeconômico Médio da Escola. A identificação das variáveis, a estatística descritiva e as formas de codificação das variáveis dicotômicas são apresentadas a seguir (Quadro 1 e Tabela 1). 


\begin{tabular}{|c|c|c|}
\hline Variável & $\begin{array}{l}\text { Tipo de Variável } \\
\text { e Codificação }\end{array}$ & Descrição \\
\hline \multicolumn{3}{|l|}{ NÍVEL 1} \\
\hline Proficiência & Contínua & Proficiência em Matemática, escore TRI \\
\hline Gênero & Dicotômica (1 = menino) & $\begin{array}{l}\text { Gênero. Obtida a partir de resposta do } \\
\text { questionário do aluno sobre seu sexo. }\end{array}$ \\
\hline NSE & Contínua & $\begin{array}{l}\text { Nível socioeconômico do aluno. Obtida } \\
\text { por TRI não paramétrica a partir de itens } \\
\text { ordinais do questionário do aluno. }\end{array}$ \\
\hline Repetência & $\begin{array}{l}\text { Dicotômica } \\
\text { (1=repetiv ao menos } 1 \text { vez) }\end{array}$ & $\begin{array}{l}\text { Repetência. Obtida a partir de resposta } \\
\text { do questionário do aluno sobre a experi- } \\
\text { ência com repetência prévia. }\end{array}$ \\
\hline \multicolumn{3}{|l|}{ NÍVEL 2} \\
\hline NSEMédio & Contínua & $\begin{array}{l}\text { Nível socioeconômico médio dos alunos } \\
\text { que estudam na mesma escola. Obtido } \\
\text { via agregação da variável NSE }\end{array}$ \\
\hline Dever de Casa & $\begin{array}{l}\text { Dicotômica }(1=\text { todos os profes- } \\
\text { sores da escola corrigem ao me- } \\
\text { nos algumas vezes o dever de casa) }\end{array}$ & $\begin{array}{l}\text { Demanda por Dever. Obtida a partir de } \\
\text { resposta dos alunos sobre a atitude dos } \\
\text { professores quanto ao dever de casa. }\end{array}$ \\
\hline Equipamentos & Contínua & $\begin{array}{l}\text { Existência e Conservação de Equipamen- } \\
\text { tos da escola. Obtida por TRI não para- } \\
\text { métrica a partir de itens ordinais do ques- } \\
\text { tionário da escola }\end{array}$ \\
\hline $\begin{array}{l}\text { Resolução de } \\
\text { Problemas }\end{array}$ & Contínua & $\begin{array}{l}\text { Ênfase em Resolução de Problema na Es- } \\
\text { cola. Obtida por TRI não paramétrica a } \\
\text { partir de itens ordinais do questionário do } \\
\text { professor }\end{array}$ \\
\hline $\begin{array}{l}\text { Liderança indutora } \\
\text { de Colaboração }\end{array}$ & Contínua & $\begin{array}{l}\text { Liderança Indutora de Colaboração Do- } \\
\text { cente. Obtida por TRI não paramétrica a } \\
\text { partir de itens ordinais do questionário do } \\
\text { professor }\end{array}$ \\
\hline Pessoal e Recursos & Contínua & $\begin{array}{l}\text { Existência de Pessoal e Recursos Finan- } \\
\text { ceiros e Pedagógicos da escola. Obtida } \\
\text { por TRI não paramétrica a partir de itens } \\
\text { ordinais do questionário do professor }\end{array}$ \\
\hline $\begin{array}{l}\text { Bom Clima } \\
\text { Disciplinar (R) }\end{array}$ & Contínua & $\begin{array}{l}\text { Bom Clima Disciplinar. Obtida por TRI não } \\
\text { paramétrica a partir de itens ordinais do } \\
\text { questionário do professor }\end{array}$ \\
\hline Biblioteca em Sala & $\begin{array}{l}\text { Dicotômica } \\
(1=\text { todas as turmas da escola } \\
\text { possuem uma pequena bibliote- } \\
\text { ca em sala) }\end{array}$ & $\begin{array}{l}\text { Biblioteca em Sala. Obtida a partir de res- } \\
\text { posta do questionário da turma sobre exis- } \\
\text { tência de uma pequena biblioteca em sala } \\
\text { para os alunos da } 4{ }^{a} \text { série. }\end{array}$ \\
\hline
\end{tabular}

\section{Quadro 1- Variáveis utilizados na modelagem.}


Tabela 1 - Estatísticas descritivas das variáveis utilizadas.

\begin{tabular}{|l|c|c|c|c|}
\hline \multicolumn{1}{|c|}{ Variável } & Média & Desvio-Padrão & Mín. & Máx. \\
\hline Proficiência em Matemática & 176.3 & 45.9 & 59.8 & 367.3 \\
\hline Gênero & 0.51 & 0.49 & 0 & 1 \\
\hline Nível Socioeconômico do Aluno (NSE) & 0,00 & 1,00 & -2.35 & 4.79 \\
\hline Repetência & 0.33 & 0.46 & 0 & 1 \\
\hline Nível Socioeconômico Médio (NSE Médio) & 0,00 & 1,00 & -2.61 & 2.89 \\
\hline Dever de Casa & 0.38 & 0.48 & 0 & 1 \\
\hline Equipamentos & 0,00 & 1,00 & -2.20 & 1.60 \\
\hline Resolução de Problemas & 0,00 & 1,00 & -5.72 & 1.20 \\
\hline Liderança Indutora de Colaboração & 0,00 & 1,00 & -5.09 & 1.62 \\
\hline Pessoal e Recursos & 0,00 & 1,00 & -2.39 & 1.39 \\
\hline Bom Clima Disciplinar & 0,00 & 1,00 & -2.54 & 1.07 \\
\hline Biblioteca em Sala & 0.31 & 0.45 & 0 & 1 \\
\hline
\end{tabular}

\section{Abordagem analítica}

Nossas questões de pesquisa estão relacionadas à identificação tanto de características escolares associadas ao aumento do desempenho médio das escolas quanto de fatores escolares que moderam o efeito da origem socioeconômica dos alunos sobre seus resultados escolares.

Face à estrutura hierárquica dos dados, na qual os alunos estão agrupados dentro de escolas, utilizamos o modelo hierárquico linear (Hierarchical Linear Model HLM), de dois níveis como abordagem analítica. Infelizmente, os dados do SAEB não suportam análise de três níveis, com alunos encaixados em turmas que, por sua vez, são encaixadas em escolas. A razão desta limitação relaciona-se com o plano amostral do SAEB, que seleciona apenas uma ou duas turmas por escola. Nos casos em que tínhamos duas turmas e diferentes prá- ticas pedagógicas em uma mesma escola, agregamos, pela média, a variável da turma para o nível da escola.

Conforme sugerido por Bryk e Raudenbush (1992), construímos nossos modelos 'de baixo para cima', especificando inicialmente um modelo totalmente incondicional, com o propósito de calcular a proporção da variância da variável dependente (proficiência em matemática) entre escolas e dentro das escolas. Dando prosseguimento à análise, estimamos um modelo com variáveis explicativas somente no nível dos alunos, ou seja, no nível-1. Neste modelo incluímos o nível socioeconômico do aluno, uma variável indicadora de experiência prévia de repetência, como controle de desempenho prévio do aluno, e um controle adicional por gênero. Na etapa final da modelagem incluímos as variáveis escolares, com o propósito de modelarmos 
tanto o intercepto (média controlada da escola) quanto o coeficiente que expressa o efeito do nível socioeconômico do aluno em seu resultado escolar. ${ }^{5}$

A modelagem do intercepto é importante para identificar características escolares associadas ao desempenho médio dos estudantes. Complementarmente, a modelagem do coeficiente associado à variável NSE nos permite verificar como a magnitude do efeito do nível socioeconômico varia entre escolas, de acordo com os recursos, práticas e políticas implementadas por cada unidade escolar. $O$ coeficiente associado à variável NSE, que pode variar de escola para escola, informa-nos sobre a eqüidade dentro das escolas. Quanto maior o coeficiente de NSE, maior a influência da origem social do aluno em seu resultado escolar e, portanto, menor a eqüidade intraescolar. Por isso, características escolares associadas a eqüidade intraescolar são aquelas que reduzem a magnitude do coeficiente da variável NSE. Complementarmente, estamos interessados em analisar o conceito de eqüidade entre escolas, ou seja, dentro do sistema educacional. Para operacionalizar este conceito é necessário observar o efeito de políticas e práticas educativas tanto sobre o intercepto quanto sobre o coeficiente associado à variável NSE: se uma determinada prática ou política escolar aumenta a média do desempenho escolar enquanto simultaneamente abaixa o coeficiente da variável NSE, podemos concluir que estamos diante de característica pró-eqüidade, uma vez que sua implementação generalizada nas escolas contribui para aumentar a média do de- sempenho, enquanto, simultaneamente, modera a influência da origem social nos resultados escolares.

Uma situação mais complexa surge quando uma prática ou política está associada ao aumento do desempenho médio, mas, simultaneamente, aumenta o coeficiente da variável NSE. Neste caso, o efeito global não é, em princípio, tão claro. Por enquanto, é suficiente adiantar que para operacionalizar a definição de eqüidade entre escolas neste caso é necessário combinar o efeito pró-eqüidade do aumento da média e o efeito antieqüidade do aumento do coeficiente da variável NSE. Mais à frente, retornaremos a este tema, detalhando esta discussão a partir dos nossos resultados.

\section{Resultados}

A estimação do modelo incondicional permite dividir a variância em dois componentes: a variância dentro das escolas e a variância entre escolas. $\bigcirc$ ajuste deste modelo indica que 39\% da variância da variável dependente (proficiência em matemática) encontra-se entre escolas. Em países europeus e nos EUA, a variância entre escolas usualmente está em torno de $20 \%$. A alta porcentagem encontrada no Brasil é um indicativo de que nosso sistema educacional é altamente estratificado, apresentando muita desigualdade entre as escolas.

modelo de nível-1 estimado á apresentado na tabela 2. Neste modelo, o intercepto representa a média geral do desempenho escolar controlado pelas variáveis do

\footnotetext{
${ }^{5}$ Usamos o procedimento usual para as especificações adicionais sobre como incluir as variáveis de nível 1 no modelo: a variável NSE, por ser modelada no nível 2, foi centrada em torno da media da escola (group mean centered) e as demais variáveis de nível-1 foram centradas em torno de suas médias globais (grand mean centered). Optamos por fixar como nula a variância entre escolas da variável de controle gênero, de modo a evitar a perda de maior números de escolas, face ao número relativamente pequeno de obsenvações dentro das escolas.
} 
aluno no modelo. O coeficiente estimado para a variável repetência indica o forte efeito negativo associado a este processo $\left(\gamma_{20}=20,4\right)$, resultado compatível com trabalhos anteriores (LEE; FRANCO; ALBERNAZ, 2004). Com relação ao gênero, os meninos têm resultados melhores do que as meninas em matemática $\left(\gamma_{30}=4,5\right)$. Este resultado apresenta-se em consonância com o indicado pela literatura educacional, que tem registrado a tendência de diferenças favoráveis aos me- ninos na área de matemática. Os resultados do PISA 2000 (OECD, 2001), por exemplo, mostraram que em 29 países dos 32 analisados, os meninos obtiveram um rendimento maior do que o das meninas e o país em que se observou a maior diferença em favor dos meninos foi justamente o Brasil. A tabela 2 apresenta também a relação positiva entre NSE do aluno e desempenho escolar $\left(\gamma_{10}=7,8\right)$, o que indica desigualdade intraescolar.

\section{Tabela 2 - Modelo inicial para a relação entre as características dos alunos e o desempenho em matemática.}

\begin{tabular}{lll}
\hline Efeitos Fixos & & Coeficiente \\
\hline Intercepto & $\gamma_{00}$ & 179.3 \\
NSE & $\gamma_{10}$ & 7.8 \\
Repetência & $\gamma_{20}$ & -20.4 \\
Gênero & $\gamma_{30}$ & 4.5 \\
\hline Efeitos Aleatórios & & Variância \\
\hline Intercepto & $\boldsymbol{u}_{0 j}$ & 466.9 \\
Inclinação NSE & $\boldsymbol{u}_{l j}$ & 89.2 \\
Inclinação Repetência & $\boldsymbol{u}_{2 j}$ & 217.5 \\
Erro Nível-1 & $\boldsymbol{r}_{i j}$ & 1224.2 \\
\hline
\end{tabular}

Obs.: Para todos os coeficientes da tabela $p<0.01$

A parte inferior da tabela 2 aborda o tema da variabilidade entre escolas dos coeficientes estimados no modelo de nível-1. Dois parâmetros são particularmente relevantes face às nossas questões de pesquisa: (1) o intercepto, que é a média do desempenho escolar, ajustada por gênero e experiência prévia de repetência e (2) o coeficiente associado à variável NSE que indica a desigualdade socioeconômica dentro das escolas. Em ambos os casos, como a variância é significativamente maior do que zero, os coeficientes variam entre escolas $^{6}$. $O$ próximo passo do processo da análise é a modelagem tanto do intercepto quanto do coeficiente de NSE, a partir da inclusão no modelo de variáveis baseadas nas características escolares, de modo a verificar seus efeitos na qualidade (intercepto) e na eqüidade socioeconômica (coeficiente de NSE). A Tabela 3 apresenta os resultados para o modelo final (Between

\footnotetext{
${ }^{6} \mathrm{O}$ coeficiente para a inclinação repetência também varia entre escolas e como a repetência é um controle da habilidade prévia,
} mantivermos este coeficiente variando aleatoriamente. 
School Model). Os coeficientes associados às variáveis do nível-1 sofreram poucas alterações se comparados aos resultados já apresentados na tabela 2. Por isso, somente mostraremos as variáveis do modelo de nível-2 na próxima tabela.

\section{Tabela 3 - Modelo multinível completo para a relação entre características dos} alunos e das escolas e o desempenho em matemática.

\begin{tabular}{lll}
\hline Efeitos Fixos & & Coeficiente \\
\hline Média das Escolas, & $\gamma_{00}$ & 181.7 \\
NSEMédio & $\gamma_{01}$ & $15.0^{*}$ \\
Dever de Casa & $\gamma_{02}$ & $12.7^{*}$ \\
Equipamentos & $\gamma_{03}$ & $4.5^{*}$ \\
Resolução de Problemas & $\gamma_{04}$ & $0.8^{* *}$ \\
Biblioteca em sala & $\gamma_{05}$ & $4.4^{*}$ \\
Liderança Indutora de Colaboração & $\gamma_{06}$ & $0.8^{* *}$ \\
Pessoal e Recursos & $\gamma_{07}$ & $0.9^{* *}$ \\
Bom Clima Disciplinar & $\gamma_{08}$ & $0.6^{* *}$ \\
Inclinação NSE/Desempenho & & \\
Intercepto & $\gamma_{10}$ & $3.01^{*}$ \\
Resolução de Problema & $\gamma_{11}$ & $0.60^{* *}$ \\
Dever de Casa & $\gamma_{12}$ & $2.30^{*}$ \\
Equipamentos & $\gamma_{13}$ & $3.03^{*}$ \\
Pessoal e Recursos & $\gamma_{14}$ & $0.84^{*}$ \\
Biblioteca em Sala & $\gamma_{15}$ & $1.99^{*}$ \\
\hline Efeitos Aleatórios & & Variância \\
\hline Intercepto & $\boldsymbol{u}_{0 j}$ & $177.4^{*}$ \\
Inclinação NSE & $\boldsymbol{u}_{1 j}$ & $55.3^{*}$ \\
\hline
\end{tabular}

Obs.: $\left({ }^{*}\right) p<0.01\left(^{* *}\right) p<=0.10$

Como vimos anteriormente, as características escolares aqui analisadas podem ser agrupadas em cinco categorias e podem possuir efeitos tanto no intercepto quanto no coeficiente associado à variável NSE. A primeira categoria refere-se à composição da escola, expressa no modelo através da média do NSE dos alunos. $O$ aumento de uma unidade na variável NSE Médio asso- cia-se, em média, a aumento de 15 pontos no rendimento dos alunos e a aumento de 3 pontos, em média, no coeficiente de NSE do aluno.

Mesmo após controle por nível socioeconômico médio, constatamos a importância de algumas características escolares no desempenho médio dos alunos. Os indi- 
cadores relacionados à categoria ênfase acadêmica - Dever de Casa, Biblioteca em Sala e Bom Clima Disciplinar - apresentam efeitos positivos no aumento do desempenho médio das escolas. A demanda por Dever de Casa está associada a um aumento médio de 12,7 pontos no resultado escolar dos alunos. A mesma variável está associada a aumento, em média, e de 2,3 pontos no coeficiente de NSE. Isto significa que, apesar de promover qualidade (via aumento da média geral), esta variável associa-se também a aumento do impacto da origem social dos estudantes sobre o desempenho escolar, gerando, assim, desigualdade dentro das escolas. A variável Biblioteca em Sala apresenta comportamento similar: a presença de uma pequena biblioteca em sala de aula associa-se a aumento médio de 4,4 pontos no desempenho escolar e a aumento de aproximadamente 2 pontos no coeficiente da variável NSE. Observa-se também que o aumento de uma unidade na variável Bom Clima Escolar acarreta um aumento médio de 0,6 ponto na media escolar. Esta variável não afetou o coeficiente de NSE.

A Tabela 3 indica que outras variáveis escolares mostram-se estatisticamente associadas ao aumento da média escolar. $\bigcirc$ aumento de uma unidade nas variáveis Liderança Indutora de Colaboração e Resolução de Problemas está associado a aumento médio de 0,8 pontos no resultado médio da escola. Adicionalmente, tanto a variável Equipamentos quanto a variável Pessoal e Recursos também estão associadas a melhores resultados médios dos alunos, seus coeficientes são, respectivamente, 4,5 e 0,9. Três dessas variáveis - Equipamentos, Pessoal e Recursos e Resolução de problemas - têm efeito sobre o modo como a variável NSE afeta o desempenho escolar dos alunos. E todas elas estão associadas ao aumento do efeito de NSE sobre o desempenho escolar dos alunos. Em resumo: em nossa análise encontramos diversas variáveis associadas a maior desempenho médio dos alunos e diversas delas afetam também o modo como a origem social dos alunos, expressa pela variável NSE, influi no desempenho dos alunos. No entanto, sempre que alguma variável mostra-se relevante tanto na modelagem da média escolar quanto do coeficiente de NSE - resultado obtido indica que as práticas e políticas associadas ao aumento da média escolar estão também associadas ao aumento da desigualdade intraescolar.

Nossos resultados indicam, portanto, que a relação entre qualidade e eqüidade em educação é complexa, pois políticas e práticas voltadas para o aumento da qualidade não têm, necessariamente, repercussão direta sobre a eqüidade intraescolar. Em outras palavras, na análise resumida na Tabela 3 apresentamos diversas variáveis indicadoras de qualidade que se mostraram, simultaneamente, como variáveis associadas ao aumento da desigualdade dentro das escolas. Para a adequada avaliação do significado deste tipo de efeito, faz-se necessário considerar o conceito adicional de eqüidade no sistema educacional. $\bigcirc$ restante deste artigo é dedicado a este tema, bem como à aplicação deste conceito adicional aos resultados que obtivemos.

A avaliação dos efeitos escolares que são associados a um aumento do desempenho médio e à moderação do efeito de origem social sobre o desempenho escolar é relativamente simples, pois se obtêm maior desempenho médio e distribuição mais 
equânime do desempenho dentro das escolas. Quando os resultados indicam, simultaneamente, maior desempenho médio e aumento do efeito da origem social no desempenho dos alunos, a avaliação da situação não pode prescindir da apuração global do efeito pró-qualidade sobre a média escolar e do efeito antieqüidade intraescolar, relativo ao aumento do efeito da origem social sobre o desempenho dos alunos da escola. Esta apuração global relaciona-se com o conceito de eqüidade no sistema educacional.

Ainda que determinadas políticas e práticas associem-se ao aumento da desigualdade dentro das escolas, elas podem ter efeito de eqüidade no sistema educacional, desde que o efeito do aumento da média da escola compense o aumento da desigualdade dentro da escola. A estimação do efeito global dentro do sistema educacional é obtida pela porcentagem de alunos que se beneficiam da difusão de uma determinada política ou prática, em comparação com o cenário contrafactual de inexistência da política ou prática em questão. Ilustramos essa discussão conceitual com o exemplo da variável Dever de Casa, já relatada na descrição de nossos resultados. Como vimos, controlada por todas as demais variáveis incluídas em nosso modelo, a ênfase da escola em passar e corrigir dever de casa associa-se a maior desempenho médio das escolas $\left(\gamma_{02}=12,7\right.$, na Tabela 3$)$. No entanto, são os alunos com maior NSE dentro das escolas que mais se benefici- am da ênfase em passar e corrigir dever de casa $\left(\gamma_{12}=2,3\right) .{ }^{7}$ No caso da variável Demanda por Dever de Casa, o cálculo da proporção de estudantes que se beneficiam desta característica, deve considerar dois grupos de estudantes. $\bigcirc$ primeiro engloba todos os estudantes cujo NSE é maior que o NSE médio da escola. Como qualquer outro estudante, estes estudantes beneficiam-se do efeito positivo da Demanda por Dever de Casa sobre o desempenho médio da escola $\left(\gamma_{02}=12,7\right)$. Beneficiam-se adicionalmente do aumento do efeito de NSE sobre os resultados dos alunos. No segundo grupo estão os estudantes com NSE menores que o NSE médio da escola. Estes alunos também se beneficiam do efeito positivo da Demanda por Dever de Casa sobre o desempenho médio da escola $\left(\gamma_{02}=12,7\right)$. Entretanto, esses alunos não se beneficiam do resultado que indica que dever de casa aumenta o efeito do NSE dos alunos sobre seus desempenhos $\left(\gamma_{12}=2,3\right)$, iá que os alunos desse segundo grupo possuem NSE menor que a média de sua escola (negativo, portanto, face à nossa decisão de centrar a variável NSE em torno da média dos alunos).

Considerando todas as outras variáveis incluídas no modelo constantes, o efeito da demanda por Dever de Casa sobre o desempenho pode ser calculado pela adição de seu efeito principal com o termo de interação entre níveis: $\left(\gamma_{02}+\gamma_{12} \mathrm{NSE}_{\mathrm{ij}}\right)$. Dado que tanto $\gamma_{02}$ e $\gamma_{12}$ são positivos, o efeito é positivo para todos os estudantes que possuem NSE positivo (acima do NSE médio

\footnotetext{
7 É importante lembrar que no modelo HLM centramos a variável NSE em torno da média da escola. Portanto, estudantes com NSE maior que a média de sua escola receberam valores positivos para NSE na análise multinível, enquanto estudantes com NSE menor que a média de sua escola possuem valores negativos para a variável NSE. Como o coeficiente associado à variável Dever de Casa, de valor positivo $\left(\gamma_{12}=2,3\right)$, será multiplicado pelo valor da variável NSE, apura-se vantagem para os alunos de NSE maior que a média de sua escola.
} 
da escola) e para todos os estudantes com NSE negativo desde que NSEii $>-\gamma_{02} / \gamma_{12}$. Baseado no valor dos coeficientes estima- dos e nos dados do NSE dos estudantes, verificamos que a Demanda por Dever de Casa é benéfico para $100 \%$ dos estudantes.

\section{Gráfico 1 - $O$ efeito da demanda por dever de casa no desempenho escolar de acordo com NSE do aluno dentro de uma mesma escola.}

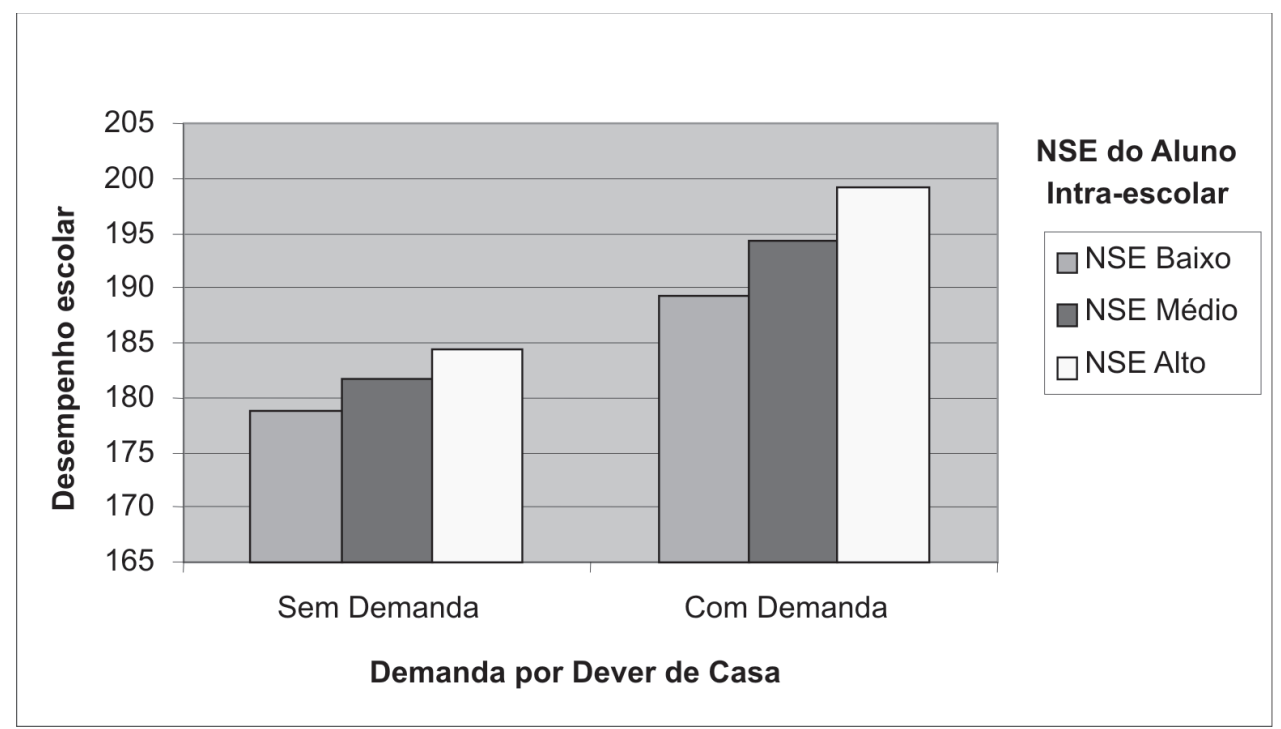

O gráfico 1 ilustra o efeito de demanda por Dever de Casa no desempenho escolar de diferentes subgrupos. ${ }^{8} \mathrm{O}$ gráfico permite que se observe: (a) o efeito positivo de demanda por Dever de Casa sobre a média escolar; (b) o efeito regressivo de demanda por dever de casa sobre a eqüidade intraescolar; e (c) o efeito positivo de demanda por Dever de casa sobre a eqüidade no sistema educacional.

Com relação às demais variáveis incluídas no modelo, realizamos o mesmo procedimento detalhado para a variável Demanda por Dever de Casa. A porcentagem de alunos que se beneficiariam com Existência e Conservação de Equipamentos, ênfase em resolução de problemas, presença de biblioteca em sala de aula e Existência de Pessoal e Recursos é, respectivamente, $98,7 \% ; 97,7 \% ; 100 \%$ e $94,3 \%$.

Finalmente, cabe informar que 0 modelo apresentado na Tabela 3 explica 62\% da variância do intercepto (media das escolas) e $38 \%$ da variância do coeficiente associado à variável NSE.

\section{Conclusões}

A revisão de literatura e os resultados obtidos na presente investigação mostram que, nos últimos anos, houve alguns progressos na pesquisa sobre os fatores intra-

\footnotetext{
${ }^{8}$ Os valores assumidos no gráfico para NSE baixo, médio e alto corresponde respectivamente ao percentil 10,50 e 90.
} 
escolares e as desigualdades na distribuição social do conhecimento, que acompanharam e, inclusive, foram além das idéias preconizadas em 1979 por Guiomar Namo de Mello em relação ao tema. Como ilustrado pela discussão conceitual e pela investigação empírica apresentadas no presente artigo, a pesquisa educacional está apta a abordar, simultaneamente, tanto as implicações de fatores intraescolares (dentro de cada escola), eventualmente afetando de modo diferenciado alunos de origens sociais distintas, quanto as implicações sobre alunos que freqüentam diferentes unidades escolares.

Os achados da presente investigação não diferem expressivamente dos resultados de outras investigações brasileiras. No entanto, face ao ainda restrito conjunto de pesquisas sobre efeito escola com dados brasileiros, consideramos salutar poder confirmar a partir dos dados do SAEB 2001, 4ª série, matemática, diversos dos achados já relatados por nós mesmos e por outros pesquisadores brasileiros que usaram outros dados. Os resultados da presente pesquisa enfatizam que a escola faz diferença, em especial por meio do clima acadêmico da escola, captado na presente investigação via variáveis que enfatizavam a ênfase em passar e corrigir dever de casa, a organização de um cantinho de livros dentro da sala de aula e a manutenção de um bom clima disciplinar, da liderança do diretor, que induzia a colaboração entre professores, e da disponibilidade de recursos na escola, captada via variáveis que mensuravam tanto a disponibilidade e conservação de equipamentos quanto a existência de pessoal e de recursos financeiros na escola. Considerando-se conjuntamente a magnitude dos coeficientes estimados, a amplitude das variá- veis explicativas associadas aos coeficientes e o desvio-padrão da variável dependente faz-se necessário mencionar que a magnitude da maior parte dos efeitos encontrados é relativamente pequena, com exceção dos efeitos associados às variáveis Dever de Casa e Equipamentos. Isso ocorre por duas razões. Em primeiro lugar, porque estamos trabalhando com dados observacionais e há forte correlação entre o controle por nível socioeconômico médio da escola e as variáveis explicativas. A este respeito, pesquisa recente da OECD (2001) apontou que - Brasil é um dos países no qual a magnitude da correlação entre composição socioeconômica da escola e melhores condições escolares é particularmente grande. A segunda razão deriva do próprio padrão de correlação entre as variáveis explicativas utilizadas, que acabavam competindo para explicar a variância da variável dependente, o que redunda na diminuição dos coeficientes estimados.

Finalmente, ressaltamos que no presente artigo desenvolvemos e ilustramos uma abordagem que permite avaliar adequadamente o efeito de políticas e práticas que aumentam a qualidade da educação, a despeito de, eventualmente, aumentar a desigualdade na distribuição social do aprendizado escolar. Para além do aspecto metodológico acerca de como avaliar esse tipo de efeito, os resultados da presente investigação, que enfatizaram que variáveis associadas ao aumento de médias escolares também se associaram ao aumento da desigualdade dentro da escola, sugerem que as políticas de qualidade em educação precisam ser acompanhadas por políticas de eqüidade intraescolar, sem o pressuposto de que políticas de qualidade equacionem automaticamente todas as dimensões da eqüidade. 


\section{Referências}

ALBERNAZ, A.; FERREIRA, F.; FRANCO, C. Qualidade e eqüidade no ensino fundamental brasileiro. Pesquisa e Planejamento Econômico, Rio de Janeiro, v. 32, n. 3, 2002.

ANDRADE, M.; FRANCO, C.; CARVALHO, J. B. P. Gênero e desempenho em matemática ao final do ensino médio: quais as relações?. In: Estudos em Avaliação Educacional, São Paulo, n. 27, jan./jun. 2003.

BONAMINO, A.; FRANCO, C.; ALVES, F. The color of educational inequalities. In: GLOBAL CONFERENCE ON EDUCATION RESEARCH FOR DEVELOPING COUNTRIES, 2005, Prague. Proceedings of the ... [S.I.: s.n.], 2005. No prelo.

BRYK, A.; RAUDENBUSH, S. Hierarchical linear models. Newbury Park: Sage, 1992.

ESPÓSITO, Y.L.; DAVIS, C.; NUNES, M. M. R. Sistema de Avaliação do Rendimento Escolar: o modelo adotado pelo estado de São Paulo. Revista Brasileira de Educação, São Paulo, n. 13, p.25-53, jan./abr. 2000.

CHOMSKY, N. The Chomsky reader. New York: Penguim, 1986.

FRANCO, C. Ciclos e letramento na fase inicial do ensino fundamental. Revista Brasileira de Educação, Rio de Janeiro, v. 25, n. 25. p. 30-38, jan./abr. 2004.

FRANCO, C. et al. O referencial teórico na construção dos questionários contextuais do SAEB 2001. Estudos em Avaliação Educacional, São Paulo, n. 28, p. 39-71, 2003.

FRANCO, C.; MANDARINO, M.; ORTIGÃO, M. I. Projeto pedagógico de escola promove eficácia e eqüidade em educação? Revista Undime-RJ, Rio de Janeiro, v. 7, n. 2 , p. 30-46, 2001.

FRANCO, C.; ORTIGÃO, M. I.; AlBERNAZ, A.; BONAMINO, A.; AGUIAR, G.; AlVES, F.; SATYRO, N. Eficacia escolar en Brasil: investigando prácticas y políticas escolares moderadoras de desigualdades educacionales. In: SANTIAGO CUETO (Org.). Educación y brechas de equidad en América Latina. Santiago: Preal, 2006.

FRANCO, C.; SZTAJN, P.; ORTIGÃO, M. I. Mathematics teachers, reform, and equity: results from the Brazilian National Assessment. Journal for Research in Mathematics Education, Reston, Virginia, n. 38, 2007. In press.

GOLDBERG, M. et al. Seletividade sócio-econômica no ensino de $1^{\circ}$ grau. Rio de Janeiro: Achiamé: Anped, 1981. 
INEP. Qualidade da educação: uma nova leitura do desempenho dos estudantes da $4^{\text {a }}$ série do ensino fundamental. Brasília, DF, 2003.

INEP. SAEB 2001: novas perspectivas. Brasília, DF, 2001.

LEE, V. E.; BRYK, A. S.; SMITH, J. The organizations of effective secondary schools. Review of Research in Education, Washington, DC, p. 171-267, 1993.

LEE, V. E.; FRANCO, C.; ALBERNAZ, A. Quality and equality in brazilian secondary schools: a multilevel cross-national school effects study. International Review of Contemporary Sociology, 2007. In press.

MAYER, D. P.; MULLENS, J. E.; MOORE, M. T. Monitoring school quality: an indicators report, NCES 2001-030. Washington, DC: U.S. Department of Education, 2000.

MELLO, G. N. Fatores intraescolares como mecanismo de seletividade no ensino de $1^{\circ}$ grau. Educação e Sociedade, São Paulo, ano I, n. 2, p. 70-78, 1979.

MELLO, G. N. Fatores intraescolares como mecanismo de seletividade no ensino de $1^{\circ}$ grau. In: GOLDBERG, M. et al. Seletividade socioeconômica no ensino de $1^{\circ}$ grau. Rio de Janeiro: Anped: Achiamé, 1981.

MENEZES-FILHO, N.; PAZELLO, E. Does money in schools matter?: evaluating the effects of a funding reform on wages and test scores in Brazil. Rio de Janeiro: PREAL,

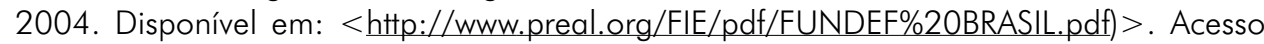
em: abr. 2007.

MORTIMORE, P. The nature and findings of school effectiveness research in primary sector. In: RIDDELL, S.; PECK, E. (Org.). School effectiveness research: its message for school improvement. Londres: HMSO, 1991.

OECD. Literacy skills for the world of tomorrow: further results from PISA 2000. Paris, 2004.

OECD. Pisa 2000: first results. Paris, 2001.

RAUDENBUSH, S. W.; BRYK, A. S. Hierarchical linear models: applications and data analysis methods. 2nd ed. Thousand Oaks, CA: Sage, 2002.

SAMMONS, P.; HILLMAN, J.; MORTIMORE, P. Key characteristics of effective schools: a review of school effectiveness research. London: Office for Standards in Education [OFSTED], 1995. 
SCHWARTZMAN, S. Brazil: the social agenda. Daedalus: journal of the American Academic of Arts and Sciences, v. 129, n. 2, p. 29-56, 2000.

SOARES, J. F. Qualidade e eqüidade na educação básica brasileira: a evidência do SAEB-2001. Archivos Analíticos de Políticas Educativas, v. 12, n. 38, 2004. Disponível em: <http://epaa.asu.edu/epaa/v12n38>. Acesso em: abr. 2007.

SOARES, J. F.; ALVES, M. T. Desigualdades raciais no Sistema Brasileiro de Educação Básica. Educação e Pesquisa, São Paulo, v. 29, p. 147-165, 2003.

SOARES, T. M. Influência do professor e do ambiente em sala de aula sobre a proficiência alcançada pelos alunos avaliados no Simave 2002. Estudos em Avaliação Educacional, São Paulo, v. 28, p. 103-123, 2003.

- Modelo de 3 níveis hierárquicos para a proficiência dos alunos de $4^{a}$ série

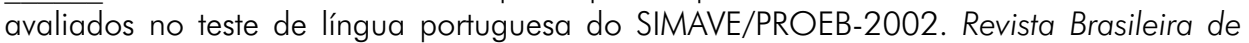
Educação. Revista Brasileira de Educação, São Paulo, v. 29, p. 73-87, 2005.

UNESCO. Laboratorio Latinoamericano de Evaluación de Calidad de la Educación. Primer Estudio Internacional Comparativo sobre lenguaje, matemática y factores asociados para alumnos del tercer y cuarto grado de la educación básica: $2^{\circ}$ informe. Santiago, Chile, 2000.

Recebido em: 02/05/2007

Aceito para publicação em: 29/05/2007 